\title{
TITULAÇÃO POTENCIOMÉTRICA APLICADA NA DETERMINAÇÃO DE ÁCIDOS GRAXOS LIVRES DE ÓLEOS E GORDURAS COMESTÍVEIS
}

\author{
Cibele Cristina Osawa* e Lireny Ap. Guaraldo Gonçalves \\ Departamento de Tecnologia de Alimentos, Faculdade de Engenharia de Alimentos, Universidade Estadual de Campinas, \\ CP 6121, 13083-862 Campinas - SP, Brasil
}

\section{Sidnei Ragazzi}

Departamento de Estatística, Universidade Estadual de Campinas, CP 6065, 13083-970 Campinas - SP, Brasil

Recebido em 6/4/05; aceito em 26/8/05; publicado na web em 16/2/06

\begin{abstract}
POTENTIOMETRIC TITRATION APPLIED TO FREE FATTY ACID DETERMINATION OF EDIBLE OILS AND FATS. Free fatty acids are a measure of evaluating fats and oils, submitted to abusive conditions, besides being a quality characteristic of edible vegetable oils. The official method of determination (AOCS Ca 5a-40, 2004) is based on titration, using phenolphthalein as an indicator. For crude and degummed oils, the titration end point is difficult to be observed due to the high level of pigments, resulting in dark solutions. In this case and others, such as self-life studies, in which sample quantities are limited, potentiometric titration may be a very good alternative.
\end{abstract}

Keywords: free fatty acid determination; potentiometric titration; oil and fat quality.

\section{INTRODUÇÃO}

\section{Determinação de ácidos graxos livres}

A medida de acidez é uma variável que está intimamente relacionada com a qualidade da matéria-prima, o processamento e, principalmente, com as condições de conservação da gordura ${ }^{1}$. Segundo a Portaria $n^{\circ} 482$ da ANVISA², o teor de acidez é uma das características de qualidade dos diversos óleos vegetais (arroz, soja, canola, milho, oliva, algodão, amendoim, girassol, uva) e gorduras (coco, babaçu, palma, palmiste) e, entre outros parâmetros, classifica os azeites de oliva em suas diversas sub-classes: virgem, extra-virgem, lampante e refinado.

Os lipídios podem sofrer transformações químicas durante o armazenamento, no processamento ou ainda no uso como meio de transferência de calor. As transformações mais importantes são a rancidez hidrolítica, rancidez oxidativa e reversão ${ }^{3}$. A rancidez, seja hidrolítica ou oxidativa, é a deterioração dos lipídios e constitui-se em um dos problemas técnicos mais importantes na indústria de alimentos.

A rancidez hidrolítica resulta da hidrólise da ligação éster por lipase ou umidade. A rancidez hidrolítica enzimática refere-se à hidrólise dos óleos e gorduras com produção de ácidos graxos livres (AGL), devido à ação das enzimas lipases, presentes nas sementes oleaginosas ou lipases de origem microbiana. De forma não enzimática, a rancidez hidrolítica se dá em altas temperaturas, produzindo ácidos graxos livres ${ }^{1}$. É acelerada por luz e calor e os ácidos graxos livres formados são responsáveis pelo sabor e odor desagradáveis, especialmente em gorduras como a manteiga, que possui grande quantidade de ácidos graxos de baixo peso molecular. Porém, em gorduras com ácidos graxos não-voláteis, o sabor e odor característicos não surgem juntamente com a deterioração. Nesse caso, é muito importante a medida quantitativa dos ácidos graxos livres para se determinar o grau de deterioração ${ }^{4}$. Um outro efeito importante decorrente do aumento do teor de ácidos graxos livres é o abaixamento do ponto de fumaça do lipídio, com reflexos sofre a inflamabilidade do mesmo ${ }^{3}$.

*e-mail: ciosawa@hotmail.com
Em relação a óleos de fritura, a medida de ácidos graxos livres é um teste relativamente simples para avaliar sua qualidade, apesar de não gerar informação completa sobre a adequação da gordura para uso posterior ${ }^{5}$. A acidez - número de $\mathrm{mg}$ de $\mathrm{KOH}$ requerido para neutralizar os ácidos graxos livres em $1 \mathrm{~g}$ de amostra ${ }^{4}-$ aumenta com o aumento da deterioração do óleo durante o processo de fritura, pois maior quantidade de ácidos graxos livres é formada e não deve ultrapassar o valor de $2,0 \%$ em ácido oléico ${ }^{6}$.

A determinação de ácidos graxos livres é dada pela porcentagem (em peso) de ácidos graxos livres, em relação a um ácido graxo específico, geralmente o ácido oléico $(\mathrm{PM}=282 \mathrm{~g})$ ou outro ácido graxo predominante na amostra. $\mathrm{O}$ procedimento está baseado na dissolução a quente da gordura em solvente e previamente neutralizado, seguido de titulação com uma solução padrão de $\mathrm{NaOH}$, na presença de fenolftaleína como indicador ${ }^{3,7}$.

Em óleos brutos e degomados, a determinação da \%AGL por titulação com indicador é operacionalmente difícil e o ponto de viragem é impreciso, uma vez que esses óleos não foram submetidos a processo de clarificação, que consiste na remoção de pigmentos como carotenóides e clorofila através de terras clarificantes, ativadas ou naturais, misturadas ou não com carvão ativado ${ }^{1}$. Os pigmentos presentes mascaram a observação do ponto de viragem da titulação com indicador, incorrendo em erros, além dos erros relativos ao uso do indicador. Embora não haja, por enquanto, proposta oficial por nenhum país, pode-se aqui sugerir a titulação potenciométrica como uma alternativa viável nesse caso e em outros, inclusive onde a quantidade de amostra disponível para análises é um fator limitante. A metodologia oficial da AOCS (Ca 5a-40, 2004) ${ }^{7}$ requer quantidades extremamente altas para sua avaliação. Por ex., para amostras com $\%$ AGL previstas na faixa de 0,00 a $0,2 \%$ ác. oléico, exige-se $56,4 \pm$ $0,2 \mathrm{~g}$ de amostra, sem contar as repetições. Em estudos de vida-deprateleira de produtos alimentícios, essa metodologia é inviável, pois a avaliação dos produtos é feita periodicamente, em intervalos bem definidos e com repetição das análises.

\section{Titulação potenciométrica $\mathbf{x}$ indicadores}

À primeira vista, pode-se pensar que a reação entre quantida- 
des equivalentes de um ácido e de uma base resultaria sempre em uma solução neutra. No entanto, isto nem sempre é verdade, devido a fenômenos de hidrólise que acompanham as reações entre ácidos fortes e bases fracas ou ácidos fracos e bases fortes. Aliado a isso, a detecção do ponto final na volumetria ácido-base pode se tornar difícil, devido a efeitos tamponantes gerados no meio reagente, que podem prejudicar a ação dos indicadores ${ }^{8}$.

$\mathrm{O}$ ponto de equivalência ( $\mathrm{PE}$ ) ocorre quando a quantidade de titulante adicionada é a quantidade exata necessária para uma reação estequiométrica com o titulado9 . No caso particular das titulações de neutralização ácido-base, os indicadores são compostos orgânicos de elevado peso molecular, que se comportam em solução aquosa como ácidos fracos (indicadores ácidos) ou bases fracas (indicadores básicos) e mudam gradualmente de coloração dentro de uma faixa estreita da escala de $\mathrm{pH}$, conhecida como zona de transição, sendo que o intervalo de viragem do indicador é representado pela Equação 1

$\mathrm{pH}=\mathrm{pK} \pm 1$

Para a seleção do indicador, é necessário conhecer o valor do $\mathrm{pH}$ do ponto final, calculado pela Equação 1, fornecido em tabelas de indicadores. Apesar dos limites indicados pela equação do ponto de viragem dos indicadores (Equação 1) serem considerados uma boa aproximação do que realmente ocorre, os limites do intervalo de $\mathrm{pH}$ de viragem dos indicadores não são descritos com rigor por essa equação, pois dependem do indicador e do observador ${ }^{8}$.

A transição é mais facilmente observada quando uma forma é incolor. Por essa razão, é de particular interesse o uso da fenolftaleína, quando aplicável, que varia de róseo a incolor ${ }^{10}$.

A fenolftaleína é o indicador do grupo das ftaleínas mais conhecido e sua fórmula estrutural é dada pela Figura 1.

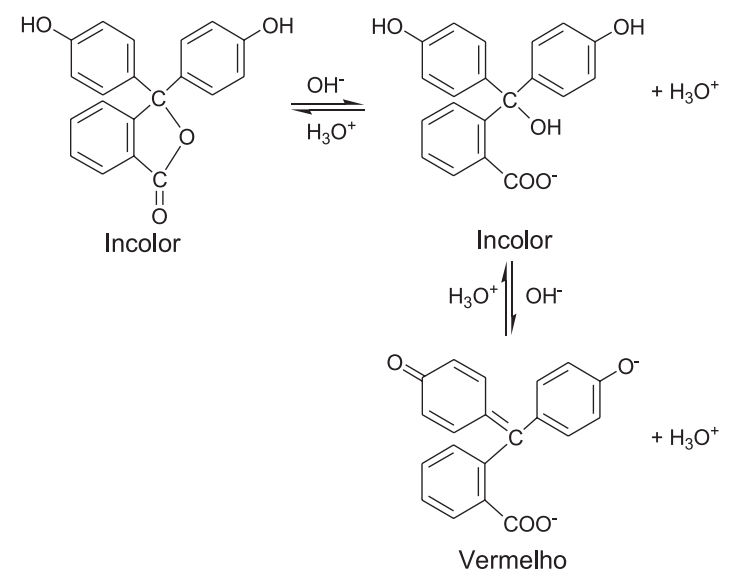

Figura 1. Fórmula estrutural da fenolftaleína

Nota-se que o anel quinóide, que confere cor à maioria dos compostos orgânicos, é formado na $2^{\mathrm{a}}$ reação. $\mathrm{O}$ pH no qual a cor rosa dessa estrutura da quinóide se torna primeiramente detectável depende da concentração do indicador e da acuidade visual do observador. Para a maioria das pessoas, entretanto, o rosa aparece na faixa de $\mathrm{pH}$ de 8,0 a $8,2^{11}$, sendo que o intervalo de $\mathrm{pH}$ da fenolftaleína compreende a faixa de 8,3 a 10,0 e seu valor de pK é de $9,6^{8}$. Nas titulações de óleos vegetais, a coloração amarelada destes resulta em uma cor derivada que não é o róseo, mas o alaranjado.

$\mathrm{O}$ erro sistemático ocorre quando o $\mathrm{pH}$ no qual a cor do indicador muda difere do $\mathrm{pH}$ da equivalência química e o erro aleatório é originado da acuidade visual do analista em distinguir reprodutivamente a cor intermediária do indicador ${ }^{11} \cdot \mathrm{O}$ erro sistemático pode ser quantificado pela Equação 2, pelo fato da mudança de cor do indicador ocorrer em um $\mathrm{pH}$ diferente do $\mathrm{pH}$ do ponto de equivalência, fazendo com que o volume titulante no ponto final $\left(\mathrm{V}_{\mathrm{PF}}\right)$ seja diferente do volume titulante no ponto de equivalência da titulação $\left(\mathrm{V}_{\mathrm{PE}}\right)$

Erro de titulação $=\frac{\mathrm{V}_{\mathrm{PF}}-\mathrm{V}_{\mathrm{PE}}}{\mathrm{V}_{\mathrm{PE}}}$

Quanto à acuidade visual do analista, somente na região em que a relação das concentrações das duas formas do indicador varia aproximadamente entre 1/10 e 10/1 é que são percebidas as mudanças de coloração $^{12}$. Em média, a incerteza visual com um indicador ácido/ básico está na faixa de $\pm 0,5$ a $\pm 1,0$ unidade de $\mathrm{pH}$, podendo ser reduzida a valores tão baixos a $\pm 0,1 \mathrm{pH}$, caso se contraste a cor da solução titulada com a cor de um padrão-referência contendo uma quantidade similar de indicador no $\mathrm{pH}$ apropriado ${ }^{11}$.

Na titulação potenciométrica, o potencial do eletrodo indicador é medido em função do volume de titulante adicionado. O ponto de equivalência da reação é reconhecido pela mudança súbita do potencial observado no gráfico das leituras de força eletromotriz (f.e.m.) contra o volume de solução titulante ${ }^{13}$.

As titulações potenciométricas requerem equipamento especial e são de execução mais demorada do que as titulações convencionais baseadas no uso de indicadores ${ }^{14}$.

As vantagens em relação aos métodos de titulação com o uso de indicadores podem ser elencadas: para titular soluções muito diluídas ${ }^{14}$; não é limitada pela cor ou turbidez de soluções que mascaram o ponto final ${ }^{13}$ e permite aproveitar certas reações para as quais a técnica convencional é impraticável em virtude da falta de indicadores apropriados ${ }^{14}$.

O presente trabalho teve como objetivos avaliar a modificação da metodologia oficial de determinação de ácidos graxos livres, substituindo a titulação com indicadores por titulação com potenciômetro, aplicada a matrizes diversas: óleos vegetais refinados, óleos brutos e degomados e gordura extraída de rações; validar o novo método através da correlação matemática com o método oficial; sugerir e divulgar outras possibilidades de utilização da nova metodologia.

\section{PARTE EXPERIMENTAL}

Foram utilizadas amostras comerciais de óleos vegetais refinados de arroz (1), algodão (2), canola (3), girassol (3), milho (3) e soja (4), obtidos no mercado local; óleos brutos e degomados de canola, soja, milho e girassol fornecidos por empresas de refino, totalizando 10 amostras, e 4 rações comerciais de cães e gatos, fornecidas por empresa do ramo.

\section{Extração da gordura de ração}

Para as amostras de ração, fez-se a extração de lipídios a frio, segundo Gutkoski e Soares Jr. ${ }^{15}$, com algumas modificações: proporção de amostra triturada e éter de petróleo de $2: 3(\mathrm{~m} / \mathrm{v})$ e aumento do tempo de contato da amostra com o solvente, de um dia para o outro, em relação aos 90 min adotados pelos autores. Após a extração, as gorduras foram acondicionadas em frascos âmbar e mantidas à $-18^{\circ} \mathrm{C}$. No dia das análises, as amostras congeladas foram imersas, uma de cada vez, em banho de água à $50^{\circ} \mathrm{C}$ para o descongelamento e a expulsão do solvente residual com a injeção de nitrogênio gasoso. A seguir, prosseguiu-se com as quantificações de $\%$ AGL. 
Os teores de ácidos graxos livres foram determinados através dos métodos oficial e modificado, em triplicata. Para ambos, as soluções de $\mathrm{NaOH}$ utilizadas foram padronizadas no dia da análise, em duplicata, utilizando biftalato de sódio seco como padrão primário, conforme Morita e Assunção ${ }^{16}$ e a solução de álcool etílico 95\% foi previamente neutralizada, de acordo com o método oficial $^{7}$. Para minimizar erros, partiu-se sempre de álcool etílico absoluto, adicionando-se 5\% de água para obtenção de álcool etílico $95 \%$.

\section{Método oficial}

Segundo procedimentos AOCS Ca $5 \mathrm{a}-40^{7}$ para as análises de óleos refinados, brutos e degomados. Usou-se $50 \mathrm{~mL}$ de álcool etílico $95 \%$, solução de $\mathrm{NaOH} 0,1 \mathrm{~N}$ e $56,4 \mathrm{~g}$ de amostra (refinados) e 28,2 g de amostra (brutos e degomados). No caso da gordura extraída de três amostras de ração, utilizou-se $30 \mathrm{~mL}$ de álcool etílico 95\%, solução de $\mathrm{NaOH} 0,05 \mathrm{~N}$ e $0,2 \mathrm{~g}$ de amostra.

\section{Método potenciométrico}

Adotaram-se procedimentos similares à metodologia oficial ${ }^{7}$, substituiu-se o indicador fenolftaleína pelo titulador "TitroLine easy" (Schott, Alemanha, 2002), ajustado para a detecção do ponto final a $\mathrm{pH}=8,8$. Ao atingir esse valor de $\mathrm{pH}$, o equipamento cessa automaticamente a adição de titulante, sem a interferência do operador. Antes do início das análises, o eletrodo de $\mathrm{pH}$ foi calibrado e adotaram-se as boas práticas de uso, fornecidas no manual do usuário do equipamento e na literatura ${ }^{9}$. As titulações de padronização das soluções de $\mathrm{NaOH}$ e da neutralização do álcool etílico $95 \%$ foram efetivadas com o uso do equipamento. Utilizou-se solução $\mathrm{NaOH} 0,1 \mathrm{~N}$ e 7,0 g de amostra para óleos brutos e degomados e soluções de $\mathrm{NaOH} 0,1 \mathrm{~N}$ e $0,05 \mathrm{~N}$, quando necessário (volume gasto inferior a $1 \mathrm{~mL}$ ao utilizar solução $0,1 \mathrm{~N}$ ) e $56,4 \mathrm{~g}$ de amostra para óleos refinados. Em ambos os casos, a quantidade de álcool etílico 95\% adotada foi de $50 \mathrm{~mL}$. Já para as três amostras de rações, as condições foram as mesmas do método oficial.

\section{Influência da quantidade de amostra no valor de \%AGL}

Para a quarta amostra de ração, determinou-se a \%AGL através do método modificado, em duplicata, variando-se a quantidade de amostra de 0,1 a $1,0 \mathrm{~g}$.

\section{Análises estatísticas}

Inicialmente foram avaliados alguns parâmetros da estatística básica: média entre repetições, desvio-padrão, coeficiente de variação, diferença relativa entre dois valores, pontos de máximo e de mínimo.

Posteriormente, para os óleos refinados, óleos brutos e degomados, foi feita, separadamente, a análise de regressão linear, a fim de comparar os valores obtidos de ácidos graxos livres, expressos em \% de ácido oléico, através do método modificado e os valores obtidos pelo método oficial.

Utilizou-se o programa Minitab for Windows versão $12.1^{17}$ para a obtenção da regressão linear pelo Método dos Mínimos Quadra$\operatorname{dos}^{18}$, assim como as bandas de $95 \%$ de confiança e de $95 \%$ de predição ${ }^{19}$.

Prosseguiu-se com os testes da regressão, do coeficiente de correlação, da inclinação (igual a 1) e do intercepto (igual a 0$)^{18,20}$.

Além da regressão linear, foi feita a Análise de Variância, utilizando o software SAS for Windows V $8^{21}$.
Para as amostras de ração, as análises estatísticas foram de caráter qualitativo.

\section{RESULTADOS E DISCUSSÃO}

\section{Óleos refinados}

Os valores de ácidos graxos livres para óleos refinados variaram de 0,028 a 0,096\%, expressos em ácido oléico (titulação com indicador), e de 0,015 a $0,063 \%$, expressos em ácido oléico (titulação com potenciômetro). A repetibilidade das determinações de ácidos graxos livres foi adequada para ambos os métodos, apresentando valores dos coeficientes de variação de 0,0 a $6,8 \%$ para o método modificado e de 0,0 a 5,0\% para a metodologia oficial.

A Figura 2 ilustra as diferenças relativas dos valores de \% AGL obtidos pelo método modificado, se comparados com os valores obtidos pelo método oficial. Houve diferença entre os métodos de $-61,0$ a $-21,2 \%$, com média de $-41,7 \pm 10,1 \%(\mathrm{CV}=24,1 \%)$.

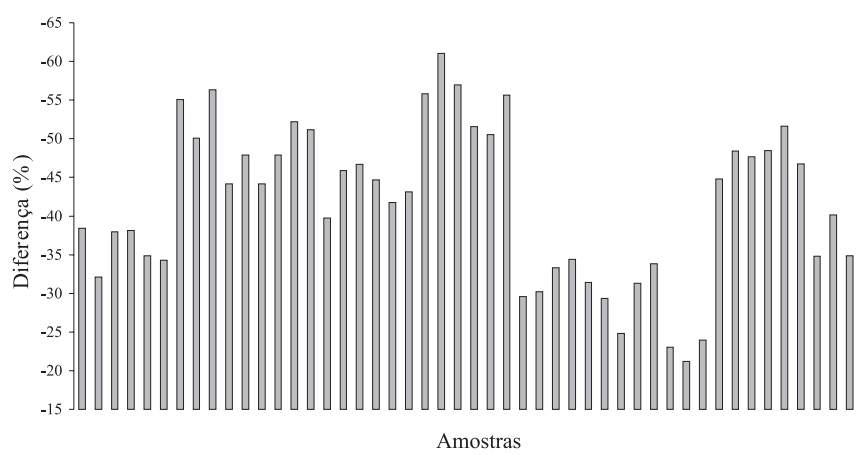

Figura 2. Diferenças relativas entre métodos, em \%, entre valores de ácidos graxos livres de óleos refinados, obtidos pelo método modificado (uso de potenciômetro) e através do método da AOCS Ca 5 a-40

\section{Regressão linear}

A equação que correlaciona o método modificado (y) com o método oficial (x), obtida pela regressão linear foi $\mathrm{y}=0,7719 \mathrm{x}-$ 0,0087 (Figura 3).



Figura 3. Correlação entre os métodos de determinação de ácidos graxos livres, utilizando titulador (método potenciométrico) e fenolftaleína como indicador (método oficial), aplicada a óleos refinados. BC e BP são, respectivamente, as bandas de confiança e as bandas de predição

O teste de regressão linear, através da análise de variância mostrou que o modelo de regressão foi bastante significativo, com valor de F igual a 482,66, superior ao valor crítico de 4,05 a nível de $5 \%$ de significância (Tabela 1). 
Tabela 1. Análise de Variância aplicada à regressão para óleos refinados

\begin{tabular}{lccccc}
\hline Fonte & GL & SQ & QM & F & p \\
\hline Regressão & 1 & 0,01037 & 0,01037 & 482,66 & 0,000 \\
Erro Residual & 46 & 0,00099 & 0,00002 & & \\
Total & 47 & 0,01135 & & & \\
\hline
\end{tabular}

$\mathrm{SQ}=$ soma dos quadrados; $\mathrm{GL}=$ graus de liberdade; $\mathrm{QM}=$ quadrados médios.

Analisando-se o valor do coeficiente de determinação $\left(\mathrm{R}^{2}\right)$, constatou-se que $91,3 \%$ da variação total dos resultados obtidos através da metodologia proposta é explicada pela reta dos Mínimos Quadrados, estando seu valor próximo ao caso ideal $\left(\mathrm{R}^{2}=1\right)$.

As hipóteses de intercepto igual a 0 e inclinação igual a 1 foram rejeitadas ao nível de 5\% de significância.

\section{Análise de Variância}

No teste F de ANOVA para comparação de médias, houve diferença significativa entre as metodologias ao nível de $5 \%$ de significância, indicando que a relação entre os valores obtidos pelo método oficial e o método modificado não corresponderam a 1 unidade. Tal fato já havia sido constatado na hipótese de inclinação igual a 1 a $1 \%$ e $5 \%$ de significância.

Ao se dividir todos os valores de \%AGL obtidos pelo método oficial pelos respectivos valores obtidos pelo método modificado, a razão obtida variou de 1,3 a 2,6, com média de $1,8 \pm 0,3(\mathrm{CV}=$ $17,6 \%)$. É interessante observar que esse intervalo inclui o valor de 1,3 , justamente o inverso do coeficiente angular.

Por tentativa e erro, ao se aplicarem fatores de correção aos resultados obtidos por potenciometria, constatou-se que os valores obtidos por potenciometria deveriam ser multiplicados por um fator de correção que variou de 1,6 a 1,7 para que não houvesse diferença significativa entre as médias das metodologias no teste de ANOVA, em nível de 5\% de significância. Isso significa que os valores de \%AGL obtidos pelo método potenciométrico foram menores, em função dos menores volumes de titulante gastos, uma vez que a titulação com fenolftaleína como indicador está associada ao excesso de titulante para que se observe visualmente o ponto de viragem. A sugestão de se multiplicar o dado potenciométrico por um fator, embora pouco elucidativo, pois não se trabalha com excesso de titulante, é aqui indicada apenas para que os resultados obtidos por esta técnica mais precisa possam ser comparados com os dados disponibilizados mundialmente com uso de indicadores, principalmente pelo fato de que a potenciometria não está sugerida como técnica oficial. O correto seria sugerir o fator aplicado de forma invertida, quem sabe factível em futuro próximo.

\section{Óleos brutos e degomados}

Em média, óleos brutos e degomados apresentaram valores de $\%$ AGL de 0,57 a 3,19\% ác. oléico (método modificado) e de 0,17 a 3,30\% ác. oléico (método oficial).

Avaliando a repetibilidade das determinações, diferentemente do que ocorreu com os óleos refinados, os valores do coeficiente de variação das análises de \%AGL dos óleos brutos através do método tradicional não se equipararam aos valores obtidos pelo método modificado (Tabela 2). Houve uma variação de 0,6 a 2,6\% para o método modificado e de 0,3 a $105,8 \%$ para o método tradicional, indicando que a falta de repetibilidade na titulação com indicador está associada a dificuldades na detecção do ponto final da titulação.

Já as diferenças relativas entre metodologias variaram de $-27,6$ a $620,9 \%$, com valor médio de $106,5 \pm 216,4 \%$ ( $\mathrm{CV}=203,2 \%)$. Na Figura 4, pode-se observar que, em geral, as diferenças foram inferiores a $50 \%$, com exceção de 8 colunas, equivalentes a 3 amostras. Tais diferenças, da ordem de seis vezes o valor de referência, são inadmissíveis, independem do analista ser treinado ou não (o mesmo analista executou todas as análises do presente trabalho) e demonstram que a determinação de \%AGL de óleos brutos e degomados através da titulação com indicador é muito problemática.

Observando os resultados obtidos por ambos os métodos na Tabela 2, para os óleos degomado de milho, bruto de canola e de soja da marca 1, o método potenciométrico gerou resultados significativamente superiores aos do método oficial (indicador). Isto porque óleos com altos teores de pigmentos, principalmente carotenóides, podem consumir visualmente quantidades menores de titulante ao utilizar o indicador do que as quantificações potenciométricas, fazendo com que surjam erros de presunção (valores sublinhados em negrito na Tabela 2). Como a viragem para róseo em meio alaranjado, como ocorre no óleo de milho bruto, por ex., resulta em cor mascarada de diferente tonalidade, o analista pode interpretar erroneamente qualquer viragem tênue de tonalidade como ponto final. Por isto, óleos de alta intensidade de cor apresentam dados de titulante superiores na metodologia potenciométrica, mesmo não havendo gasto de titulante em excesso.

Vale ressaltar que o teor de pigmentos dos óleos brutos e degomados é elevado. O óleo bruto de canola possui teor de clorofila de 5 a $25 \mathrm{mg} / \mathrm{kg}^{22}$. Outras fontes mencionam teor de clorofila de $7 \mathrm{mg} / \mathrm{kg}$ para o óleo bruto de canola e de $60 \mathrm{mg} / \mathrm{kg}$ para o óleo degomado de canola ${ }^{23}$, teor de carotenóides de 25 a $50 \mathrm{mg} / \mathrm{kg}$ para canola e 40 a $50 \mathrm{mg} / \mathrm{kg}$ para a $\operatorname{soja}^{24}$.

Tabela 2. Valores médios de \%AGL, expressos em \% ácido oléico, e seus respectivos CV, em \%, de óleos brutos e degomados, obtidos pelo método modificado (potenciometria) e pelo método oficial (indicador)

\begin{tabular}{|c|c|c|c|c|}
\hline \multirow[t]{2}{*}{ Amostra de óleo } & \multicolumn{2}{|c|}{ Método Modificado } & \multicolumn{2}{|c|}{ Método Oficial } \\
\hline & \%AGL (\% ác. oléico) & $\mathrm{CV}(\%)$ & \%AGL (\% ác. oléico) & $\mathrm{CV}(\%)$ \\
\hline degomado de canola & 1,04 & 0,9 & 1,08 & 6,6 \\
\hline degomado de girassol & 2,16 & 1,5 & 2,29 & 1,2 \\
\hline degomado de milho & $\underline{2,12}$ & 1,2 & $\underline{0,40}$ & 41,2 \\
\hline degomado de soja & $\overline{0,82}$ & 2,6 & $\overline{0,89}$ & 3,2 \\
\hline bruto de milho - marca 1 & 1,95 & 0,7 & 2,04 & 0,8 \\
\hline bruto de canola & $\underline{1,49}$ & 0,6 & $\underline{0,53}$ & 105,8 \\
\hline bruto de soja - marca 1 & $\underline{0,57}$ & 0,7 & $\underline{0,17}$ & 22,9 \\
\hline bruto de soja - marca 2 & $\overline{0,95}$ & 2,0 & $\overline{1,15}$ & 3,3 \\
\hline bruto de soja - marca 3 & 1,04 & 2,3 & 1,40 & 1,1 \\
\hline bruto de milho - marca 2 & 3,19 & 0,6 & 3,30 & 0,3 \\
\hline
\end{tabular}






Amostras

Figura 4. Diferenças, em \%, entre valores de ácidos graxos livres de óleos brutos e degomados, obtidos pelo método modificado (uso de potenciômetro) e através do método da AOCS Ca 5 a-40 (com indicador)

\section{Regressão linear}

A equação da reta, obtida pela regressão linear (mínimos quadrados) foi $\mathrm{y}=0,609 \mathrm{x}+0,724$, onde y se refere ao método modificado e $\mathrm{x}$, ao método oficial.

$\mathrm{O}$ modelo de regressão linear, através do teste $\mathrm{F}$ da ANOVA, foi significativo (Tabela 3). O valor de $\mathrm{F}$ foi de 33,44, superior ao valor crítico $(4,20)$.

Tabela 3. Análise de Variância aplicada à regressão para óleos brutos e degomados

\begin{tabular}{lccccc}
\hline Fonte & GL & SQ & QM & F & p \\
\hline Regressão & 1 & 9,67 & 9,67 & 33,44 & 0,000 \\
Erro Residual & 28 & 8,09 & 0,29 & & \\
Total & 29 & 17,76 & & & \\
\hline
\end{tabular}

$\mathrm{SQ}=$ soma dos quadrados; $\mathrm{GL}=$ graus de liberdade; $\mathrm{QM}=$ quadrados médios.

As hipóteses de intercepto igual a 0 e inclinação igual a 1 foram rejeitadas para 5\% de significância.

$\mathrm{O}$ valor do coeficiente de correlação encontrado para óleos brutos e degomados não foi tão elevado quanto o valor obtido para os óleos refinados (Figura 5). Cerca de $50 \%$ da variação total dos resultados obtidos através da metodologia proposta é explicada pela reta dos mínimos quadrados.

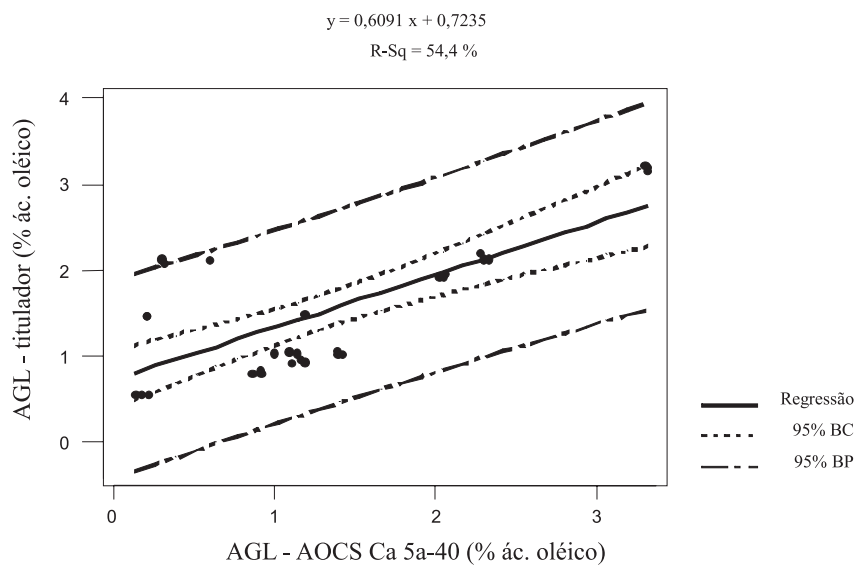

Figura 5. Correlação entre o método de determinação de ácidos graxos livres, utilizando titulador (método potenciométrico) e fenolftaleína como indicador (método oficial), aplicado a óleos brutos e degomados. BC e BP são, respectivamente, bandas de confiança e bandas de predição
Análise de variância

Em nível de $1 \%$ de significância, não houve diferença significativa entre as médias das metodologias de determinação de \%AGL, aplicadas a óleos brutos e degomados. Como o valor experimental obtido para a inclinação (igual a 0,609 ) foi estatisticamente distante de 1, esperava-se, assim como ocorreu para os óleos refinados, ser necessário aplicar fatores de correção para os valores obtidos com o uso do titulador.

Aliado a isso, deve-se atentar para as bandas de confiança e de predição mais amplas (tolerando uma faixa maior de valores) no caso dos óleos brutos e degomados (Figura 5) do que para os óleos refinados (Figura 3). As amplitudes das bandas de confiança e de predição variam de acordo com o ajuste correspondente da reta: retas cujos valores de $\mathrm{R}^{2}$ são da ordem de 0,95 possuem amplitudes relativamente pequenas, ao passo que para retas com valores relativamente baixos de $\mathrm{R}^{2}$ são responsáveis pelas maiores amplitudes dos intervalos de confiança e de predição ${ }^{19}$.

Daí, conclui-se que a \%AGL dos óleos brutos e degomados gerada pelo método oficial é pouco confiável, fato não somente atribuído à análise estatística conflitante, como também aos erros inerentes à titulação com indicador e à interferência dos pigmentos presentes nesses óleos. Dados de cor Lovibond estão disponíveis internamente em laboratórios do setor produtivo, porém difíceis de serem publicados em trabalhos científicos. A Tabela 4 apresenta um precioso compilado de valores de cor Lovibond ${ }^{1}$ de óleos vegetais, em várias etapas do refino, obtidos de alguns raros trabalhos publicados onde é possível avaliar a eliminação dos pigmentos interferentes com o decorrer do refino de óleos vegetais, visualizando principalmente a diminuição nos valores da cor vermelha $(\mathrm{R})$.

Quanto à \%AGL de óleos brutos e degomados, as informações obtidas com o emprego do titulador foram mais precisas, já que a grande quantidade de pigmentos interferiu na detecção do ponto de viragem do indicador e isso foi constatado até mesmo para técnicos altamente treinados. Dois tipos de erros podem ter ocorrido: o da presunção (o volume gasto foi inferior ao volume requerido) e o da camuflagem do ponto de viragem (dispêndio de grandes quantidades de titulante).

No presente caso, cerca de $30 \%$ das determinações de \%AGL para óleos brutos e degomados foram afetadas de forma muito significativa. Em situações em que a exatidão dos valores de \%AGL é essencial, as consequiências podem ser até mesmo de ordem econômica. No processo de refino, por ex., a medida de \%AGL é um dos parâmetros de escolha do teor e da concentração da solução de $\mathrm{NaOH}$ usada na etapa de neutralização. A obtenção de um valor de \%AGL superior ao valor real acarreta prejuízos econômicos, decorrente dso uso de maior quantidade e concentração de $\mathrm{NaOH}$, favorecendo a formação indesejável de sabões. Na condição oposta, onde se tem a subestimação do valor de \%AGL, a neutralização não é eficaz, pois se utiliza solução mais diluída e em menor quantidade, podendo resultar em um produto final de baixa aceitação e de baixo valor comercial.

\section{Rações}

\section{Método modificado x método oficial}

Comparando os valores de \%AGL das gorduras extraídas de rações, os valores médios obtidos pela metodologia modificada estão muito próximos aos respectivos valores médios obtidos pelo método convencional (Tabela 5). Os coeficientes de variação foram relativamente baixos para ambos os métodos, variando de 1,0 a 5,6\% e 1,1 a 2,2\%, respectivamente, para os métodos modificado e oficial. $\mathrm{O}$ mesmo pode ser dito para as diferenças entre metodologias, apresentando o valor médio de $13,1 \pm 3,1 \%$ e a variação de 8,0 a $17,8 \%(\mathrm{CV}=23,3 \%)$. 
Tabela 4. Cor Lovibond de óleos vegetais nas diversas etapas do refino

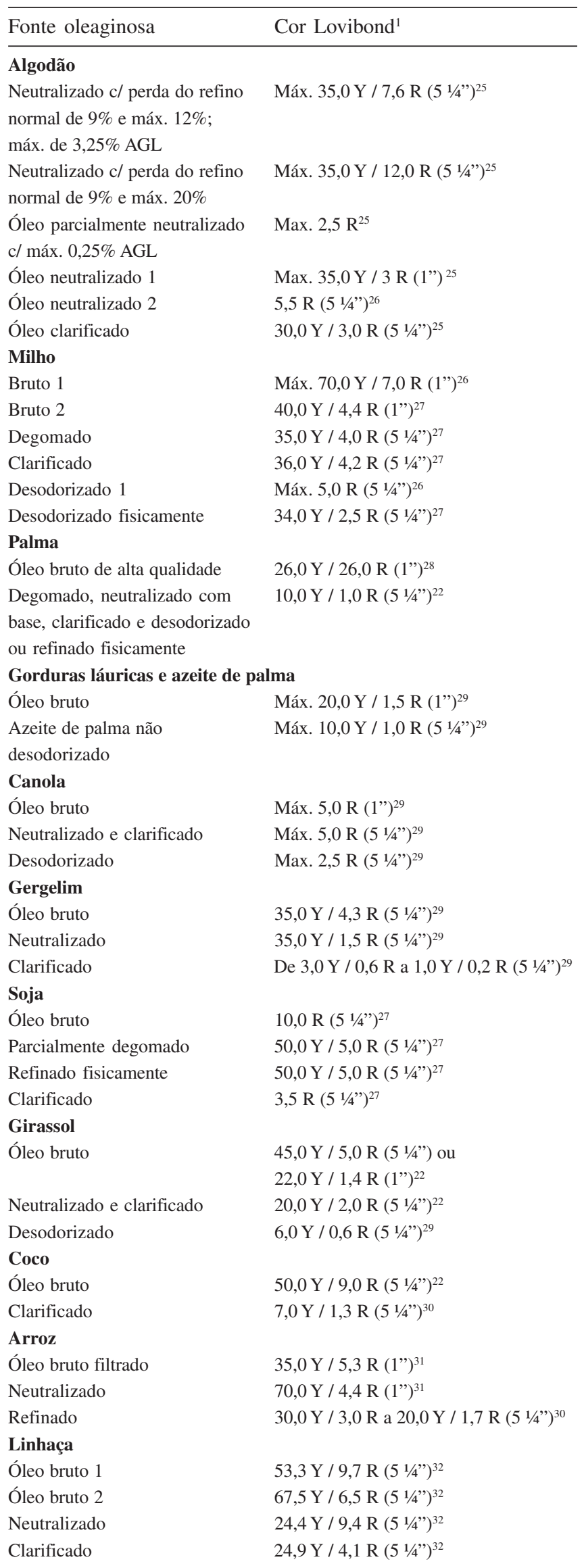

Tabela 5. Determinação de ácidos graxos livres, em \% ácido oléico, através do método oficial e do método modificado para três amostras de ração (A, B e C)

\begin{tabular}{lccc}
\hline Amostra & $\begin{array}{c}\text { \%AGL } \\
\text { (método modificado) }\end{array}$ & $\begin{array}{c}\text { \%AGL } \\
\text { (método da AOCS) }\end{array}$ & $\begin{array}{c}\text { Diferença } \\
(\%)\end{array}$ \\
\hline A & 5,46 & 4,71 & 15,9 \\
& 5,40 & 4,82 & 11,9 \\
B & 5,35 & 4,71 & 13,5 \\
& 22,85 & 20,50 & 11,5 \\
& 23,01 & 20,91 & 10,1 \\
C & 24,55 & 20,85 & 17,8 \\
& 8,64 & 7,50 & 15,1 \\
& 7,85 & 7,27 & 8,0 \\
& 8,68 & 7,59 & 14,4 \\
\hline
\end{tabular}

Alterando as quantidades de amostra utilizadas

De acordo com a Tabela 6, os valores obtidos de \%AGL para uma mesma amostra, fazendo-se variar a massa de gordura utilizada na análise, pouco diferiram entre si. A diferença entre o valor obtido para a menor (média da duplicata) e a maior massa foi de $7,1 \%$. Tal fato sugere a possibilidade de se variar a quantidade de óleo/gordura analisada, sem alterar significativamente os valores de \%AGL, quando empregada a titulação potenciométrica.

Tabela 6. Determinação de ácidos graxos livres, em \% ácido oléico, através do método modificado, variando a quantidade de amostra utilizada no teste

\begin{tabular}{lcc}
\hline Massa $(\mathrm{g})$ & $\begin{array}{c}\text { Volume gasto } \\
\text { na titulação }(\mathrm{mL})\end{array}$ & $\begin{array}{c}\text { \%AGL } \\
(\% \text { ác. oléico })\end{array}$ \\
\hline 0,5149 & 1,53 & 3,61 \\
0,5251 & 1,54 & 3,56 \\
0,2236 & 0,64 & 3,48 \\
0,2208 & 0,64 & 3,52 \\
0,1120 & 0,34 & 3,69 \\
0,1169 & 0,34 & 3,54 \\
1,0021 & 3,19 & 3,87 \\
0,8913 & 2,85 & 3,89 \\
\hline
\end{tabular}

Outra constatação foi a ordem de grandeza do volume titulado gasto ao se empregar o método modificado (Tabela 6). Na titulação com indicador, tais valores são considerados relativamente baixos, sendo o volume gasto a principal causa da baixa repetibilidade entre os valores de uma mesma amostra. Dependendo do teor de ácidos graxos livres, o volume de uma gota de titulante (equivalente a aproximadamente $0,05 \mathrm{~mL}$ ) é suficiente para gerar elevados valores de coeficientes de variação. Dessa forma, para baixos valores de ácidos graxos livres, o erro da análise é elevado e a titulação com potenciômetro constitui-se em uma alternativa valiosa.

\section{Aplicações diversas da nova técnica}

Além dos óleos brutos e degomados avaliados neste estudo, merece atenção especial o óleo de palma, cujos teores de pigmentos são bastante significativos e interferem na detecção visual do ponto final da titulação para obtenção das medidas de \%AGL. O teor de carotenóides do óleo de palma é de cerca de 500 a 1600 mg/ $\mathrm{kg}^{24}$. O óleo de palma da variedade tenera, oriunda do Pará e da Bahia, possui de 900 a $1140 \mathrm{mg} / \mathrm{kg}$ e de 550 a $650 \mathrm{mg} / \mathrm{kg}$ de carotenóides, respectivamente ${ }^{33}$. Já as amostras do Zaire e da Malásia possuem 
teor de carotenóides de 500 a $700 \mathrm{mg} / \mathrm{kg}$, enquanto que para a variedade dura da Nigéria, essa faixa é de 800 a $1600 \mathrm{mg} / \mathrm{kg}^{34}$.

Outro exemplo de difícil visualização do ponto final da titulação relacionado à cor do óleo se dá no monitoramento de \%AGL durante o processo de fritura ${ }^{35}$. Ao longo do tempo de fritura, ocorre aumento na tonalidade da cor do óleo. O óleo de soja, inicialmente com valores de cor Lovibond ${ }^{1}$ 3,0 Y / 0,3 R, com o decorrer de 6, 14, 20 e $24 \mathrm{~h}$ de fritura passou para 9,0 Y / 0,9 R; 20,0 Y / 2,2 R; 32,0 Y / 3,0 R e 55,0 Y / 5,0 R, respectivamente. Após a reposição com óleo novo, após $24 \mathrm{~h}$ de fritura, os valores de cor passaram a ser 10,0 Y / 1,9 R. Decorridas 32, 37 e $44 \mathrm{~h}$ de fritura, os valores de cor aumentaram para 24,0 Y / 4,0 R; 40,0 Y / 4,8 R e 40,0 Y / 5,9 R, respectivamente ${ }^{36}$.

Por outro lado, o uso do potenciômetro na análise de ácidos graxos livres permite maior flexibilidade de aplicações, quando a quantidade de amostra é um fator limitante ou os valores de ácidos graxos livres são relativamente baixos. Dessa forma, pode ser utilizado satisfatoriamente na avaliação da qualidade do produto final e na predição da vida útil de diversos produtos que contenham lipídios. Esse último caso merece atenção especial, uma vez que requer quantidades significativas de amostras, caso fosse computada a amostragem analisada a intervalos regulares de tempo e suas repetições, já que uma única determinação não é significativa.

Um outro ponto a ser considerado é o fato dos Ministérios da Agricultura e da Saúde do Brasil estabelecerem legislações diferentes. O MAPA regulamentou como tipificação a \%AGL máxima de $0,03 \%$ em ácido oléico em óleos desodorizados ${ }^{37}$. Para valores dessa grandeza, titulações errôneas a olho nu são possíveis de ocorrerem e podem levar à aplicação de multas e recolhimento de amostras indevidamente.

\section{CONCLUSÕES}

A técnica proposta de determinação de ácidos graxos livres com o uso de titulador mostrou-se altamente eficaz, com os resultados se correlacionando com a determinação de \%AGL através do método oficial, utilizando a fenolftaleína como indicador, para óleos vegetais refinados. $\mathrm{O}$ mesmo comportamento foi obtido para óleos brutos e degomados, cujas duas metodologias se correlacionaram. No entanto, as diferenças entre os valores chegaram a ordem de $620 \%$, fato que pode ser explicado pelo elevado teor de pigmentos desses óleos e faz com que a titulação com indicador se torne pouco confiável e alerta para a necessidade de uma técnica objetiva de determinação, que não dependa da acuidade visual do analista envolvido. Sendo assim, o método potenciométrico pode ser satisfatoriamente empregado na determinação de \%AGL de óleos com alto teor de pigmentos. Esse fato se torna essencial em amostras com elevado teor de pigmentos, como óleos brutos e degomados e óleos de fritura, cujo processo acarreta aumentos nos valores de cor ao longo do tempo.

Em caráter qualitativo, os resultados obtidos com o método potenciométrico, fazendo-se variar a quantidade de massa de amostra ( 0,1 a 1,0 g), e comparativamente com o método oficial, aplicados a rações mostraram-se uma alternativa útil quando há a limitação de quantidades de amostras.

\section{AGRADECIMENTOS}

À CAPES (Coordenação de Aperfeiçoamento de Pessoal de Nível Superior) pelo auxílio-pesquisa.

\section{REFERÊNCIAS}

1. Hui, Y. H.; Bailey's Industrial Oil \& Fat Products, $5^{\text {th }}$ ed., Wiley: New York, 1996, vol. 4
2. http://www.anvisa.gov.br/legis/resol/482_99.htm, acessada em Setembro 2003.

3. Bobbio, P. A.; Bobbio, F. O.; Química do Processamento de Alimentos, $3^{\mathrm{a}}$ ed., Varela: São Paulo, 2001, cap. 3.

4. Cecchi, H. M.; Fundamentos Teóricos e Práticos em Análise de Alimentos, $2^{\text {a }}$ ed., Ed. da Unicamp: Campinas, 2003, cap. 9.

5. Berger, K. G.; PORIM Technol. 1984, 9, 1.

6. Firestone, D. Em Deep Frying: Chemistry, Nutrition, and Practical Applications; Perkins, E. F.; Erickson, M. D., eds.; AOCS: Champaign, 1996, cap. 6.

7. AOCS; Official methods and recommended practices of the American Oil Chemists'Society, AOCS: Champaign, 2004.

8. Baccan, N.; Andrade, J. C. de; Godinho, O. E. S.; Barone, J. S.; Química Analítica Quantitativa Elementar, $3^{\mathrm{a}}$ ed., Edgard Blücher: São Paulo, 2001, cap. 3.

9. Harris, D. C.; Análise Química Quantitativa, 5 ed., LTC: Rio de Janeiro, 2001, cap. 7 e 15.

10. Christian, G. D.; Analytical Chemistry, $5^{\text {th }}$ ed., Wiley: New York, 1994, cap. 7.

11. Skoog, D. A.; West, D. M.; Holler, F. J.; Fundamentals of Analytical Chemistry, $7^{\text {th }}$ ed., Harcourt College: Orlando, 1997, cap. 10.

12. Ohlweiler, O. A.; Química Analítica Quantitativa, $3^{\mathrm{a}}$ ed., LTC: Rio de Janeiro, 1981, vol. 2.

13. Mendham, J.; Denney, R. C.; Barnes, J. D.; Thomas, M. J. K. Em VOGEL Análise Química Quantitativa; 6a ed., LTC: Rio de Janeiro, 2002, cap. 10.

14. Ohlweiler, O. A.; Química Analítica Quantitativa, LTC: Rio de Janeiro, 1974, vol. 3.

15. Gutkoski, L. C.; Tese de Doutorado, Universidade Estadual de Campinas, Brasil, 1997; Soares Júnior, M. S.; Tese de Doutorado, Universidade Estadual de Campinas, Brasil, 2000.

16. Morita, T.; Assumpção, R. M.; Manual de Soluções, Reagentes \& Solventes: Padronização, Preparação, Purificação, $11^{\mathrm{a}}$ ed., Edgard Blücher: São Paulo, 2001.

17. Ryan Júnior, R. A.; Joiner, B. L.; Ryan, B. F.; Minitab Student Handbook, Duxbury: Massachusets, 1976; Minitab Reference Manual: Release 10 for Windows, Minitab: Pennsylvania, 1994, vol. 1; Minitab User's Guide: Release 10 for Windows, Minitab: Pennsylvania, 1994.

18. Montgomery, D. C.; Design and Analysis of Experiments, $3^{\text {rd }}$ ed., Wiley: Singapure, 1991; Costa Neto, P. L. O.; Estatística, $12^{\mathrm{a}}$ ed., Edgard Blücher: São Paulo, 1992, cap. 8.; Montgomery, D. C.; Peck, E. A.; Introduction to Linear Regression Analysis, $2^{\text {nd }}$ ed., Wiley: New York, 1992.

19. Charnet, R.; Freire, C. A. de L.; Charnet, R. M. R.; Bonvino, H.; Análise de Modelos de Regressão Linear, Ed. da Unicamp: Campinas, 1999.

20. Matner, R. R.; Fox, T. L.; McGiver, D. E.; Curiale, M. S.; J. Food Protection 1990, 53, 145.

21. Council, K. A. Em SAS Introductory Guide, $3^{\text {rd }}$ ed.; Helwig, J. T., ed.; SAS Institute: Cary, 1985, cap. 11.

22. Tautorus, C. L.; Low, N. H.; J. Am. Oil Chem. Soc. 1994, 71, 1123.

23. Prior, E. M.; Vadke, V. S.; Sosulski, F. W.; J. Am. Oil Chem. Soc. 1991, 68,401 .

24. Swern, D.; Bailey's Industrial Oil and Fat Products, Wiley: New York, 1979, vol. 1.

25. Industrial Processing of Cotton-Seed apud ref. 29.

26. Europa's Quality Acceptance apud ref. 29.

27. Forster, A.; Harper, A. J.; J. Am. Oil Chem. Soc. 1983, 60, 265 apud ref. 29.

28. MacLellan, M.; J. Am. Oil Chem. Soc. 1983, 60, 368 apud ref. 29

29. Patterson, H. B. W.; Handling and Storage of Oilseeds, Oils, Fats and Meal, Elsevier: New York, 1989.

30. Patterson, H. B. W.; Bleaching and Purifying Fats and Oils: Theory and Practice, AOCS: Champaign, 1992.

31. Reddi, P. B. V.; Murti, K. S.; Feuge, R. O.; Ibid 1948, 25, 206 apud ref. 30 .

32. Osawa, C. C.; Coutinho, C. de M.; Ribeiro, A. P. B.; Cáceres, M. C.; Gonçalves, L. A. G.; Resumos do Simpósio Internacional "Tendências e Inovações em Tecnologia de Óleos e Gorduras”, Campinas, Brasil, 2003.

33. Lago, R.; Hartman, L.; Bol. Pesquisa Embrapa-CTAA 1987, 14, 7 apud Augusto, A. L. C.; Tese de Mestrado, Universidade Federal do Pará, Brasil, 1992.

34. Goh, S. H.; Choo, Y. M.; Ong, S. H.; J. Am. Oil Chem. Soc. 1985, 62, 130 apud Augusto, A. L. C.; Tese de Mestrado, Universidade Federal do Pará, Brasil, 1992.

35. Hui, Y. H. Em ref. 1, vol. 3.

36. Lima, J. R.; Tese de Mestrado, Universidade Estadual de Campinas, Brasil, 1994; Lima, J. R.; Gonçalves, L. A. G.; Quim. Nova 1994, 17, 392.

37. http://www.engetecno.com.br/legislacao/geral_oleo_soja.htm, acessada em Novembro 2004. 